\title{
Long-Term Expression of the Biologically Active Growth Hormone in Genetically Modified Fibroblasts after Implantation into a Hypophysectomized Rat
}

\author{
BING-FANG CHEN, ${ }^{1}$ WEN-CHANG CHANG, ${ }^{2}$ SHUI-TSUNG CHEN, ${ }^{2}$ DING-SHINN CHEN, $, 3,4$ and \\ LIH-HWA HWANG ${ }^{1,3}$
}

\begin{abstract}
We employed the hypophysectomized rats as an animal model to explore the feasibility of using genetically engineered fibroblast cells for growth hormone gene therapy. An internal ribosome entry site (IRES)-directed bicistronic retroviral vector, PSN, which contained a porcine growth hormone (pGH) cDNA at the first cistron and a $\mathrm{Neo}^{\mathrm{r}}$ gene at the second cistron was used to infect primary rat embryo fibroblast (REF) cells. The infected cells $\left(5 \times 10^{6}\right.$ cells/rat) were injected directly into the peritoneum of syngeneic hypophysectomized rats. We demonstrate that the implanted PSN-infected REF cells could secrete biologically active pGH in vivo, leading to significant growth of the tibia at day 15 and day 57 post-implantation. We also treated the PSNinfected REF cells with collagen to form a tissue-like structure. The skin-like discs were grafted underneath the skin on the back of rats and cells were retrieved at different times. Using two criteria, semiquantitative reverse transcription-polymerase chain reaction on the pGH RNA extracted from the explants and G418 resistance conferred from the explanted cells, we demonstrate that pGH was expressed in the implanted fibroblasts up to 70 days. Despite the fact that the total pGH RNA level was reduced in the explants of longtime post-implantation, which was probably due to the reduction of transduced cells retained in the explants, the specific efficiencies of pGH RNA expression from these explants were maintained as high as the primary PSN-infected REF prior implantation. These results suggest that fibroblast cells are capable of expressing the foreign genes persistently in vivo.
\end{abstract}

\section{OVERVIEW SUMMARY}

Primary fibroblast cells are the potential target cells for transducing secretory proteins for gene therapy purpose because of their easy access to the circulation. In this paper, we demonstrate a sustained expression of porcine growth hormone (pGH) from the implanted rat embryo fibroblast cells for at least $\mathbf{7 0}$ days in an animal model of growth hormone deficiency. These results, as improved from previous findings, might raise issues regarding careful evaluation of primary fibroblast cells for human gene therapy.

\section{INTRODUCTION}

$\mathbf{T}$ HE ADENOPHYPOPHYSIS secretes growth hormone ( $\mathrm{GH}$, also known as somatotropin), a hormone that affects the rate of skeletal growth and gain in body weight. Hyposecretion of GH in humans may cause dwarfism or premature arresting of skeletal development (Martin, 1973). Treatment for pituitary dwarfism is usually repeated subcutaneous injections of $\mathbf{G H}$ (Laron et al., 1971). Therefore, it would represent an important advance to develop a cellular transplantation system that could stably produce and deliver such a recombinant protein into the systemic circulation. To deliver a gene product such as GH to the circulation, many different cells can be chosen for practical considerations. Particularly, the target cells must be easily accessed, grown, transfected with a recombinant gene in vitro, and finally conveniently reimplanted into the host. These cells should produce enough amounts of secreted proteins, and, after secretion, this protein should be able to gain access to circulation. These requirements suggest that the fibroblast cell is one of the most attractive targets for gene therapy.

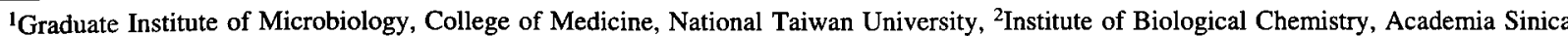
and Institute of Biochemical Sciences, National Taiwan University, ${ }^{3}$ Hepatitis Research Center, and ${ }^{4}$ Department of Internal Medicine, National Taiwan University Hospital, Taipei, Taiwan, R.O.C.
} 
Several reports have shown the feasibility of this approach by transplanting the gene-transduced fibroblast cell lines into the laboratory animals, and detecting the expression of the heterologous proteins in the circulation (Garver et al., 1987; Selden et al., 1987; Rosenberg et al., 1988; Tani et al., 1989). However, the cell lines could be tumorigenic in animals and expression can be observed only for a short time. Recently, some laboratories started trying to transplant the genetically engineered primary fibroblast cells into the syngeneic animals. Their results indicated that production of proteins, either the human clotting factor IX (St. Louis and Verma, 1988) or the human adenosine deaminase (ADA) (Palmer et al., 1991), in primary embryo fibroblasts or in skin fibroblast cells, respectively, for $>1$ month was not achievable. The gradual decrease in protein levels might be caused by an immune response against the foreign protein (St. Louis and Verma, 1988) or inactivation of the transduced genes (Palmer et al., 1991). On the other hand, there was also a report illustrating the long-term (up to 8 weeks) expression of human factor VIII mediated by the retrovirus-infected skin fibroblast cells in immunodeficient mice (Hoeben et al., 1993). Therefore, whether or not the primary fibroblast cells can support a long-term expression remains obscure.

In this study, we intend to develop a cellular GH delivery system in an animal model to investigate the feasibility of a long-term expression of the transduced gene via the implanted primary fibroblast cells. The animal model for GH deficiency is a hypophysectomized rat. It has been known for some time that hypophysectomy causes a decrease in epiphysial cartilage width in the immature rat (Dott and Fraser, 1923; Ray et al., 1941), and that administration of the extracts from the anterior pituitary lobe partially reverses this effect (Dott, 1923; Handelsman and Gordon, 1930; Smith, 1930). Freud and coworkers further found that the pituitary $\mathrm{GH}$ increased the thickness of the tibia growth plate, which primarily stimulates the proliferation of chondrocytes (Freud et al., 1939). Other hormones, such as insulin and thyroid hormones, may also influence bone growth, but GH is the only recognized hormone that stimulates longitudinal bone growth in a dose-dependent manner over a wide range of doses (Kibrick et al., 1941). Based on these phenomena, a sensitive and specific bioassay of GH activity, determining the tibia growth plate width in the hypophysectomized rats, was developed (Evans et al., 1943; Greenspan et al., 1949), and it is now still used as one of the reference methods for determining $\mathrm{GH}$ activity in vivo. The GH studied in this work is a good target because most of the GHs sequenced from different species show a high degree of homology (Wilhelmi, 1974), and thus alleviate the problem of immune response when a particular GH is used in a xenospecies system. In addition, GH from all mammalian species promotes growth in the hypophysectomized rat and is active in the rat tibia bioassay (Wilhelmi, 1974). In this study, we used the cDNA coding for porcine growth hormone (pGH) as a reporter gene. Using a bicistronic retroviral vector that expressed pGH in high levels (Chen et al., 1993) to infect primary rat embryo fibroblast (REF) cells, we demonstrate that, after implantation of the virus-infected REF into the hypophysectomized rats, pGH activity was observed in vivo and the implanted cells continuously expressed pGH-specific RNA for up to 70 days.

\section{MATERIALS AND METHODS}

\section{Cell culture}

All cultures were maintained in Dulbecco's modified Eagle's medium (DMEM) with high glucose (4.5 grams/liter) supplemented with $10 \%$ fetal calf serum (FCS) at $37^{\circ} \mathrm{C}$ in a $5 \% \mathrm{CO}_{2}$ incubator. The cells used included an ecotropic retrovirus packaging cell line, GP + E - 86 (Markowitz et al., 1988), the NIH$3 \mathrm{~T} 3$ cell line, and primary REF. The primary REF were prepared from 17- to 18-day-old Brown Norway rat embryos by the cold trypsin method (Fresheny, 1983). After culturing for 1-2 days, the primary culture was immediately frozen in liquid nitrogen until use. To avoid potential complications of in vitro aging, the primary culture was immediately used for infection after thawing. Normally, it was considered as the passage 2 (P2) of the primary culture.

\section{Preparation of recombinant retroviruses}

The backbone of the retroviral vector was derived from the N2 vector (Armentano et al., 1987). The Tn5 neomycin resistance gene $\left(\mathrm{Neo}^{\mathrm{r}}\right)$ and a poly(A) signal-excluded cDNA that codes for $\mathrm{pGH}$ were used in the construction of the retroviral vector. Plasmid N5 (see Fig. 2A) is a single gene vector that is similar to N2; however, it contains a shortened, but functional, $\mathrm{Neo}^{\mathrm{r}}$ gene in between two long terminal repeats (LTRs). PSN (see Fig. 2A) is a bicistronic retroviral vector that contains the pGH cDNA at the first cistron and the $\mathrm{Neo}^{\mathrm{r}}$ gene at the second cistron. SVDV represents the 742-bp-long $5^{\prime}$ nontranslated region of the cDNA fragment of the swine vesicular disease virus (SVDV), a member of the Picornavirus family, which can internally initiate the translation of second cistron, i.e., the $\mathrm{Neo}^{\mathrm{r}}$ gene. Construction of the PSN vector has been described in detail previously (Chen et al., 1993). Recombinant retroviruses were produced by transfecting $2 \times 10^{5}$ of $\mathrm{GP}+\mathrm{E}-86$ ecotropic packaging cell line with $20 \mu \mathrm{g}$ of plasmid DNA (Chen et al., 1993). Viruses were harvested 16-18 hr after fresh medium was placed onto the nearly confluent virus-producing cells, and were used to infect NIH-3T3 cells to determine the viral titer or to infect REF target cells for implantation.

\section{Infection of primary REF for implantation}

After thawing, $1 \times 10^{5}$ of primary REF cells of the P2 generation were immediately infected with $1 \mathrm{ml}$ of PSN or N5 viruses. In all, four consecutive infections were performed in 4

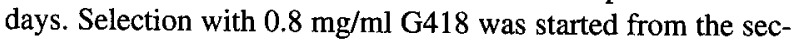
ond day post initial infection and was continued for 2 weeks. Normally, the mock-infected REF cells completely died after 2 weeks selection, whereas the PSN- or N5-infected REF grew to confluence. The G418-resistant REF cells were either used directly for intraperitoneal injection or were treated with collagen for 1 week more to form a dermal graft. In general, the REF cells used were around $20-30$ population doublings at the time of implantation.

\section{Purification of $p G H$ protein from cultured medium}

The virus-infected NIH-3T3 cells secreting large amounts of pGH were grown in multitrays until confluence was reached, 
and they were then placed in serum-free DMEM. Proteins from the supernatant were precipitated with an equal volume of 3.8 $M\left(\mathrm{NH}_{4}\right)_{2} \mathrm{SO}_{4}$ and subsequently dissolved in phosphatebuffered saline (PBS). The solution was subjected to Sephacryl S-200 gel filtration $(2.5 \times 100 \mathrm{~cm})$ with PBS as the eluant. Fractions containing pGH were pooled and quantitated using a Bio-Rad protein assay. The purity of the preparation was determined by a SDS-polyacrylamide gel, and the activity of pGH was determined by the tibia bioassay.

\section{Bioassay of $p G H$}

A standard bioassay for GH was performed as previously described (Evans et al., 1943; Greenspan et al., 1949). In brief, immature Brown Norway female rats were hypophysectomized when 26-28 days old. Post operation, the body weights of the hypophysectomized animals were minitored at intervals of 2 days for a period of 14 days. Animals with no apparent body weight increase were chosen for further bioassay experiments. Known amounts of recombinant pGH or a total of $5 \times 10^{6}$ of the virus-infected REF were injected intraperitoneally. At the times indicated in the results, the animals were sacrificed and the width of the tibia from each autopsied animal was measured under the microscope. The significant differences of the biological activity between each tested sample were determined by the Student $t$-test analysis.

\section{ELISA for $p G H$}

Rabbit anti-pGH serum was obtained by immunizing rabbits intrasplenically (Hong et al., 1989) and was kindly provided by W.C. Chang. In the enzyme-linked immunosorbent assay (ELISA), standard pGH (a gift from International Mineral Corp.) at several known concentrations and culture medium samples were first coated onto 96-well plates. Rabbit antiserum (1:10,000 dilution) was added and allowed to react with pGH at $37^{\circ} \mathrm{C}$ for $1 \mathrm{hr}$. After removal of the first antibody by four washes with PBS, a second antibody, goat anti-rabbit immunoglobulin antibody conjugated with horseradish peroxidase, was added (1:3,000 dilution) for further $1 \mathrm{hr}$ of incubation. The plates were washed again thoroughly with PBS, and $100 \mu \mathrm{l}$ of substrate solution ( $2 \mathrm{mg}$ of $o$-phenylenediamine dissolved in $1 \mathrm{ml}$ of $1 \mathrm{M}$ phosphate citrate $\mathrm{pH} 5.0$ plus $0.02 \%$ $\mathrm{H}_{2} \mathrm{O}_{2}$ ) was added for development. After $30 \mathrm{~min}, 100 \mu \mathrm{l}$ of 1 $M \mathrm{H}_{2} \mathrm{SO}_{4}$ was added immediately to stop the reaction and the colors were measured by optical density at $492 \mathrm{~nm}$. A standard pGH curve based on the optical density at $492 \mathrm{~nm}$ of a known pGH concentration was plotted, and the concentration of pGH in our samples were obtained by interpolation from the standard curve.

\section{Western blot analysis}

To analyze the pGH protein translated from the infected culture, cells were grown in a $10-\mathrm{cm}$ dish until confluent and washed twice with PBS. A serum-free medium, Iscove's modified Dulbecco's medium, was used to refresh the cells overnight. The overnight-culture medium was collected, concentrated by Amicon Centriprep-10, and subjected to SDS$12.5 \%$ polyacrylamide gel electrophoresis (Laemmli, 1970).
Proteins were transferred from the gel to a nitrocellulose filter (Burnette, 1981). The pGH protein was reacted with rabbit antipGH serum and subsequently with an alkaline phosphatase-conjugated second antibody, goat anti-rabbit immunoglobulin G. The blot was then developed with nitroblue tetrazolium and 5bromo-4-chloro-3-indolylphosphate for a few minutes until color developed.

\section{Implantation of infected REF into the animals}

Two methods were adopted to implant the PSN-infected REF. First, a total of $5 \times 10^{6}$ cells were harvested from culture, washed with PBS, resuspended in $3 \mathrm{ml}$ of serum-free DMEM, and directly injected into the peritoneum of the hypophysectomized rats. Alternatively, $1 \times 10^{6}$ cells were cast in collagen matrices as described (Bell et al., 1979). Briefly, the cells were trypsinized, resuspended in $1 \mathrm{ml}$ of DMEM, and mixed with $0.25 \mathrm{ml}$ of $0.1 \mathrm{~N} \mathrm{NaOH}, 1.5 \mathrm{ml}$ of collagen solution $(1 \mathrm{mg} / \mathrm{ml}$ dissolved in $0.1 \%$ acetic acid), $1 \mathrm{ml}$ of fetal calf serum, $1 \mathrm{ml}$ of $5 \times \mathrm{DMEM}$, and $0.35 \mathrm{ml}$ of $5 \% \mathrm{NaHCO}_{3}$. Then $5 \mathrm{ml}$ of the mixture of fibroblasts with collagen and medium was placed in a $60-\mathrm{mm}$ plastic petri dish and incubated for 3 days in a $37^{\circ} \mathrm{C}$ incubator. The resulting matrix was contracted to a disc of about $0.5 \mathrm{~cm}$ in diameter, and was grafted into the loose connective tissue of the dermis on the backs of recipient Brown Norway rats. The second method provides the possibility of retrieving the grafts when needed. For analysis, the explanted tissues were first treated with collagenase to recover single cells. The cells were divided into three unequal parts, 6/10 for RNA extraction, 3/10 for genomic DNA extraction, and $1 / 10$ for $\mathrm{G} 418$ selection.

\section{Reverse transcription-polymerase chain reaction analysis of pGH RNA from the explanted tissue}

The pGH RNA level in the explanted tissue was analyzed by a semi-quantitative reverse transcription-polymerase chain reaction (RT-PCR). Total RNA was extracted from a 6/10 volume of explanted tissue by the acid-guanidinium isothiocyanate method (Chomczynski and Sacchi, 1987). One microgram of total RNA was used to synthesize the first-strand cDNA with random primers and avian myeloblastosis virus (AMV) reverse transcriptase (Promega, Madison, WI) in a total volume of 25 $\mu l$. The reaction was carried out at $42^{\circ} \mathrm{C}$ for $1 \mathrm{hr}$. An aliquot $(1 / 50)$ of the RT reaction was adjusted to contain $0.1 \mu \mathrm{g}$ of each primer and additional buffer was added for a total volume of $50 \mu 1$. PCR amplification was performed for 20 cycles $\left(95^{\circ} \mathrm{C}\right.$, $1 \mathrm{~min} ; 52^{\circ} \mathrm{C}, 2 \mathrm{~min}$; and $72^{\circ} \mathrm{C}, 3 \mathrm{~min}$ ). The primers used included a pair of pGH-specific primers, CCTTGTCCAGCCTATTTGCC and ACCCGCAGGTATGTCTCAGC, as well as a pair of glyceraldehyde-3-phosphate dehydrogenase (GAPDH)specific primers, ACCACAGTCCATGCCATCAC and TCCACCACCCTGTTGCTGTA. The GAPDH is a universal transcript in every cell and was used as an internal control of RT-PCR. The amplified products were separated on a $2.5 \%$ agarose gel, transferred to a Nytran membrane and hybridized with the pGH- and the GAPDH-specific probes, respectively. Band intensities (arbitrary units) were determined by a desitometer with computer analysis (Bio-Rad video densitomer, model 620). Usually several exposures of each gel without sat- 
urating the film intensities were analyzed. The band intensity of GAPDH was used to correct for the difference in the amplification variation between samples (see Fig. 3A).

\section{Analysis of genomic DNA extracted from the explanted tissue}

High-molecular-weight DNA was extracted from a 3/10 volume of the explanted cells by proteinase $\mathrm{K}$ digestion, phenol/ chloroform extraction, and ethanol precipitation (Sambrook et al., 1989). Aliquots of DNA $(0.05 \mu \mathrm{g})$ were subjected to semiquantitative PCR amplification with $\mathrm{PGH}$ and GAPDH primer sets as described above. The products were separated on a $2.5 \%$ agarose gel, transferred to a Nytran membrane, and hybridized with the pGH and the GAPDH probes, respectively. Similar quantitation of the band intensities was performed as described in RT-PCR analysis.

\section{RESULTS}

\section{Efficient expression of $p$ GH from a bicistronic retroviral vector in primary $R E F$}

We have previously characterized three types of retroviral vector in comparison of their efficiencies of coexpressing two genes in NIH-3T3 cells (Chen et al., 1992, 1993). Two reporter genes, $\mathrm{Neo}^{\mathrm{r}}$ and a cDNA coding for porcine growth hormone (pGH), were included in the constructions (Fig. 1). The $\mathrm{X}$ series represents the conventional vectors, which include an internal promoter within the long terminal repeat (LTR) transcriptional unit. The B series consists of U3-based vectors which contain the internal promoter at the $3^{\prime} \mathrm{U} 3$ region, thus allowing the promoter to be duplicated and transferred to the 5 ' LTR after one cycle of reverse transcription (Hantzopoulos et al., 1989; Chen et al., 1992). The $P$ series represents the single-gene-type vectors in which an internal ribosome entry site (IRES) derived from SVDV, a member of the family Picornaviridae, is included in the transcriptional unit, thus allowing the second cistron to be initiated internally (Chen et al., 1993). The results summarized in Fig. 1 indicate that expression of pGH from the U3-based vector was higher than the conventional vector, but, at the expense of viral titer. On the other hand, expression of pGH was most efficient from one of the bicistronic vector, PSN, while keeping the viral titer as high as the single gene vector $\mathrm{P}$. The PSN bicistronic vector containing the pGH cDNA at the first cistron and a $\mathrm{Neo}^{\mathrm{T}}$ gene at the second cistron (Fig. 2A) was thus further used to infect primary REF. As anticipated, the Moloney murine leukemia virus (MoMuLV) LTR expressed the RNA efficiently in REF (Fig. 2B). The results of Western analysis were also consistent with

\begin{abstract}
Series of retroviral vector Structure

$X$ - series

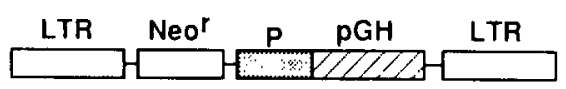

(P : CMV, SV40, TK)

B - series

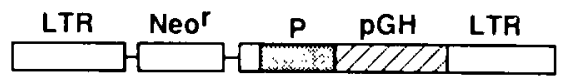

(P : CMV, SV40, TK)

P - series

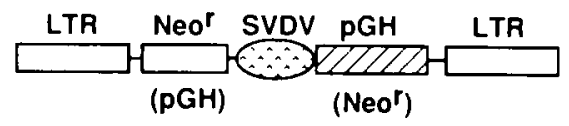

Single gene

$\stackrel{\text { LTR }}{\text { PGH }} \stackrel{\text { LTR }}{\square}$

pGH expression in NIH 3T3 cells

$\underline{\text { Vector }} \underline{\text { Titer (cfu/ml) }}$ (ng/106 cells/day)

$\begin{array}{ccc}\text { CX } & 3 \times 10^{4} & 62 \\ \text { SX } & 1.3 \times 10^{5} & 24 \\ \text { TX } & 10^{5} & 20\end{array}$

CB $10^{3} \quad 362$

SB $\quad 5 \times 10^{3} \quad 181$

$\begin{array}{lll}\text { TB } & 10^{3} & 158\end{array}$

$\begin{array}{lrr}\text { NSP } & 10^{5} & 24 \\ \text { PSN } & 10^{5} & 744 \\ & & \\ \text { P } & 10^{5} & 680\end{array}$

FIG. 1. Comparison of three types of retroviral vector. The three types of retroviral vector were constructed as described previously (Chen et al., 1992, 1993). The internal promoter, P, used included the cytomegalovirus (CMV) immediately early gene promoter (C), the SV40 early gene promoter (S), and the herpes simplex virus thymidine kinase gene promoter (T). The corresponding retroviral constructs in the X-series and B-series were thus designated as CX, SX, and TX, as well as CB, SB, and TB, respectively. The P-series, a single gene type vector, contains an internal ribosome entry site derived from the SVDV cDNA in the retroviral vector. Two constructs, NSP and PSN, included the $\mathrm{Neo}^{\mathrm{r}}$ gene and the pGH cDNA at the first and the second cistron, respectively, or vice versa. The single gene vector $\mathrm{P}$ contains only one reporter gene, $\mathrm{pGH}$. The viral titers (cfu/ml) were determined by infecting the NIH-3T3 cells with culture supernatant and the number of G418-resistant colonies were counted. The pGH expression was determined by ELISA.
\end{abstract}


A
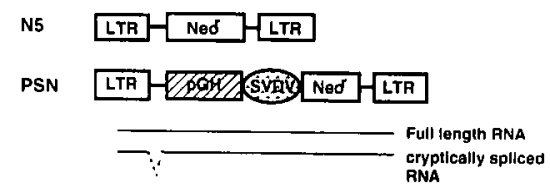

B

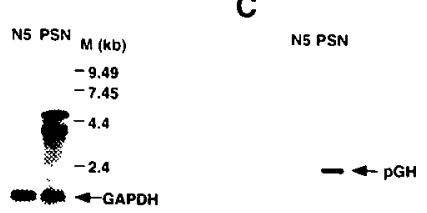

FIG. 2. Expression of PSN retroviral vector in REF. A. The constructs of N5 and PSN vectors. The structures of the N5 vector control and the PSN vector are shown. Two RNA transcripts, the full-length as well as the cryptically spliced RNA, are predicted to be transcribed from the proviral genome. B. The Northern blot analysis of the N5 virus- and PSN virus-infected REF. Five micrograms of total RNA were analyzed in each lane. The filter was hybridized with pGH and GAPDH probes. The upper two bands correspond to the full-length and the cryptically spliced RNA. Arrow indicates the GAPDH RNA. C. The Western blot analysis. Proteins collected from the culture supernatant as described in Materials and Methods were analyzed with rabbit anti-pGH antibody. The band specific for $\mathrm{pGH}$ is indicated by the arrow.

that of the Northern blot analysis, demonstrating high levels of pGH secretion in the culture medium (Fig. 2C). The secretion rate as determined by ELISA could be up to $1,180 \mathrm{ng} / 10^{6}$ cells $/ 24 \mathrm{hr}$.

\section{Biological activity of the recombinant $p G H$ produced from the cultured cells}

To further test whether the recombinant pGH produced from the infected cells was active, the PSN virus was used to infect
NIH-3T3 cells. Positive clones were selected and then expanded by multitray culture. The $\mathrm{pGH}$ protein was purified from the cultured medium as described previously (Hwang et al., 1992), and its biological activity was assayed by a standard assay measuring the tibia growth (Evans et al., 1943; Greenspan et al., 1949) (Table 1). Two doses, i.e., $20 \mu \mathrm{g}$ and $80 \mu \mathrm{g}$, of the purified pGH were injected intraperitoneally into the hypophysectomized rats. Twenty-four hours after injection, the animals were sacrificed and the width of tibia growth plate was measured. In sham operation group, animals were underwent the similar surgical operation as the hypophysectomized rats except the pituitary glands were not removed; thus, these animals represent the positive control. The recombinant $\mathrm{pGH}$ gave a dose-dependent response similar to that of the standard pGH, Zn-pGH (a gift from the International Mineral Corp., USA), as compared with that of PBS control. These results demonstrated that the pGH secreted from the virus-infected cells was biologically active.

\section{The in vivo activity of $p G H$ secreted from the implanted $p G H$-engineered REF}

We next tested the pGH biological activity from the implanted cells. Primary REF cells were first infected with the PSN virus followed by selection with G418. Immediately after selection, a total of $5 \times 10^{6}$ of the infected cells were harvested and directly injected into the peritoneum of hypophysectomized rats. At days 15 and 57 after cell implantation, rats were sacrificed and the width of the tibia of animal was measured by silver nitrate staining. As summarized in Table 2, the average width of tibia growth plate from animals implanted with PSNinfected REF was apparently wider than that from animals implanted with the $\mathrm{N} 5$ control at both time points. The differences between these two groups were significant $(p<0.01$ and $p<$ 0.05 for 15 days and 57 days post-implantation, respectively). Although the increase in body weight in the group implanted with PSN-infected cells was not as much as that of the sham group, this parameter, however, was not very informative be-

Table 1. Biological Activity of the PGH Purified from the Cultured MEDIUM

\begin{tabular}{llcc}
\hline Group & Treatment & $\begin{array}{c}\text { Width of } \\
\text { Number } \\
\text { of rat }\end{array}$ & $\begin{array}{c}\text { tibia growth } \\
\text { plate }(\mu \mathrm{\mu m})^{\mathrm{b}}\end{array}$ \\
\hline 1 & PBS & 6 & $155.0 \pm 22.9$ \\
2 & pGH-20 & 5 & $187.2 \pm 5.02$ \\
3 & pGH-80 & 5 & $210.0 \pm 11.6$ \\
4 & Zn-pGH-20 & 5 & $168.0 \pm 22.5$ \\
5 & Zn-pGH-80 & 5 & $202.8 \pm 25.3$ \\
6 & Sham operation & 5 & $189.6 \pm 11.1$ \\
\hline
\end{tabular}

apBS means that phosphate-buffered saline was i.p. injected into the hypophysectomized rats; pGH-20 and pGH-80 indicate that $20 \mu \mathrm{g}$ and $80 \mu \mathrm{g}$, respectively, of the culture medium-derived recombinant pGH were injected; $\mathrm{Zn}-\mathrm{pGH}-20$ and $\mathrm{Zn}-\mathrm{pGH}$ 80 indicate that $20 \mu \mathrm{g}$ and $80 \mu \mathrm{g}$, respectively, of the standard $\mathrm{Zn}$-form pGH were injected; sham operation means that the rats underwent similar operation procedure, but the pituitary glands were not removed.

bThe values represent the mean widths \pm SEM. The difference between values for PBS control and the culture medium-derived recombinant pGH $(20 \mu \mathrm{g}$ and $80 \mu \mathrm{g})$ $(p<0.05)$ as well as those for the two doses of $\mathrm{pGH}, 20 \mu \mathrm{g}$ and $80 \mu \mathrm{g}(p<0.05)$, were all significant. 
Table 2. The In Vivo Bioassay of PGH Secreted from Implanted REF

\begin{tabular}{lccrr}
\hline $\begin{array}{l}\text { Days post- } \\
\text { implantation }\end{array}$ & Treatment & $\begin{array}{c}\text { Number } \\
\text { of rat }\end{array}$ & $\begin{array}{c}\text { Width of } \\
\text { tibia growth } \\
\text { plate }(\mu \mathrm{m})^{\mathrm{c}}\end{array}$ & $\begin{array}{c}\text { Increase in } \\
\text { body weight } \\
(\%)\end{array}$ \\
\hline 15 days & Sham $^{\mathrm{a}}$ & 5 & $172.0 \pm 10.4$ & 30.50 \\
& N5 $^{\mathrm{b}}$ & 4 & $85.0 \pm 12.1$ & -0.25 \\
57 days & PSN $^{\mathrm{b}}$ & 6 & $149.9 \pm 19.0$ & 4.82 \\
& Sham & 5 & $127.3 \pm 12.8$ & 49.90 \\
& N5 & 6 & $93.4 \pm 10.0$ & -0.15 \\
& PSN & 4 & $143.0 \pm 27.6$ & 5.04 \\
\hline
\end{tabular}

aRats were sham-operated without cell implantation.

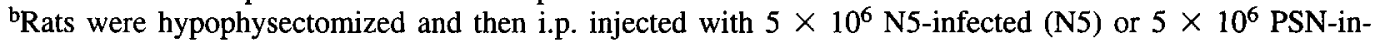
fected (PSN) REF.

${ }^{c}$ The values represent the mean widths \pm SEM. The differences between values for N5 and sham control as well as N5 and PSN were very significant in the groups of 15 days post-transplantation $(p<0.01)$ and significant in the groups of 57 days post-transplantation $(p<0.05)$.

cause it also involved many extrinsic factors, such as nutrition, environment, care, and effects from many other pituitary hormones, etc. Even so, the results still support the biological activity of pGH in vivo as compared with rats receiving N5-transduced REF cells. The results indicated that we successfully established an animal model to assay the growth hormone function in vivo.

\section{Long-lasting expression of $p G H$ in hypophysectomized rats}

Because tibia growth increases during the first 6-8 days of treatment with $\mathrm{GH}$ until the normal equilibrium between chondrogenesis and osteogenesis is reestablished (Kibrick et al., 1941), and because bone growth is an irreversible process, the observation of an increase in tibia width at day 15 and day 57 post-implantation cannot distinguish whether it is a past or a current pGH activity. To understand whether the pGH expression was persistent in the implanted REF, we tested an alternative method of implantation. PSN-infected REF cells were cast in collagen matrices as previously described (Bell et al., 1979) and used as a dermal equivalent graft. The retrievable dermal grafts thus enabled us to analyze whether pGH expression could last for long period in vivo. Four grafts were placed underneath the skin on the back of rats at four different sites. The skin was then directly sutured. For analysis, one graft was retrieved each time at day 5 , day 15 , day 42 , and day 70 post implantation. The expression of pGH from the explanted grafts was determined by two criteria.

First, semiquantitative RT-PCR analysis was performed on the tissue RNA extracted from the explants. Although PCR analysis could not be used for precise quantitation, if we performed the reaction only for 20 cycles which still kept the reaction in the linear amplification range, the products generated may reflect the amount of cDNA semiquantitatively. To determine the quantitative nature of this technique, we first analyzed the band intensities of RT-PCR products from known amounts of RNA. The results shown in Fig. 3A indicate a linear correlation of the intensities of RT-PCR products to the percentages of RNA level in the samples. Similarly, the correlation between the DNA PCR products and the percentages of vector DNA also existed. As a result, the pGH-specific RNA level in each explant was analyzed by similar technique (Fig. 3B). It was noted that at day 5 and day 15, expression of pGH from 3 independent animals (lanes 4-6 and lanes 7-9, respectively) was maintained as high as that from the primary PSN-infected REF prior implantation (lane 3); at day 42 and day 70 , the level of pGH RNA was greatly reduced (lanes $10-12$ and lanes 13-15, respectively). It dropped to around 5-7\%. The low levels of signal at day-42 and day-70 explants, however, could not be a contamination of genomic DNA in the RNA preparation because no PCR products could be detected when the reverse transcriptase was omitted from the RT-PCR reaction (lanes 16-18).

To understand further the status of the vector DNA in the explanted tissues, we also performed a semiquantitative PCR analysis on the genomic DNA prepared from the explanted grafts (Fig. 3C). Consistent with the RT-PCR results, the signals specific for $\mathrm{pGH}$ sequence were also markedly reduced in the grafts after long time post-implantation. Interpolating from the calibration curve, the results indicate that only 5-8\% of vector DNA were retained in the day- 42 and the day- 70 explants. Therefore, if we normalized the pGH RNA levels with the residual DNA copies retained in the grafts, the specific expression efficiencies of pGH RNA from the day-42 and the day-70 explants were actually maintained as equivalent as the primary PSN-infected REF prior implantation (lane 3), thus indicating a long-lasting expression of pGH in vivo.

Second, we measured the ability of the explanted tissues to form G418-resistant cultures in vitro. Grafts that were removed at day 5 and day 15 easily produced G418-resistant colonies from all 3 rats. However, grafts that were removed at day 42 and day 70 formed much fewer G418-resistant colonies from all three animals. The relative ratio of G418-resistant colonies formed from day- 5 or day- 15 explants to those from day -42 or day-70 explants was around 10-20, which was quite correlated with the percentages of vector positivity in these explants (Fig. $3 \mathrm{C}$ ). To understand further the pGH expression in these G418resistant clones, cells were expanded and RNA expression was checked by Northern blot. Because the vector employed in this study is a bicistronic retroviral vector that comprises only the 
LTR promoter, the fact that G418-resistant culture could be established from the grafts not only indicated that the transduced cells were viable in the explants, but also indicated that the LTR promoter was transcriptionally active. We then anticipated that pGH expression should be sustained as well. The results shown in Fig. 4 demonstrate that no gross alteration in pGH RNA level from all the G418-resistant cells obtained from day-5 to day70 explants (lanes 4-15) was observed as compared to that of the primary PSN-infected REF prior implantation (lane 3). In addition, pGH secretion from all these G418-resistant cells was as high as that of the primary PSN-infected REF (data not shown). These results indirectly suggested that the viral vector

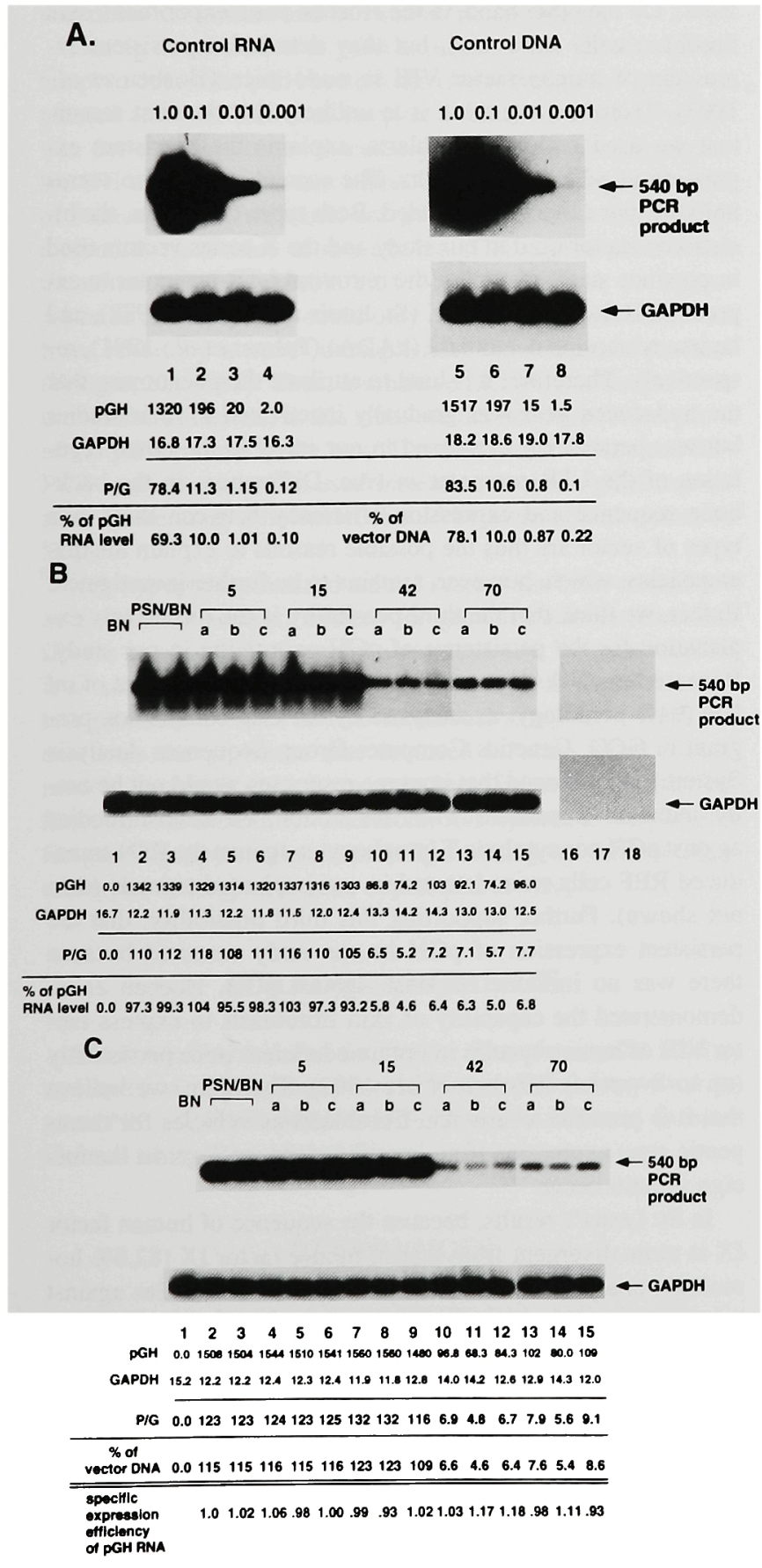

was persistently transcriptionally active up to 70 days in vivo. Although we could not exclude the possibility that viral vector was reversibly inactivated in vivo but was reactivated soon after explantation, we tempted to believe that the LTR promoter was persistently active in vivo because vector-specific transcript could readily be detected in the day-70 explants by RT-PCR analysis (see the above results). From these data, we conclude that $\mathrm{pGH}$ expression was sustained for at least 70 days in vivo.

\section{DISCUSSION}

Many different primary cells, including skin fibroblast cells (St. Louis and Verma, 1988; Palmer et al., 1991), keratinocytes (Fenjves et al., 1989; Morgan et al., 1987; Gerrard et al., 1993), epithelial cells (Smith et al., 1991), endothelial cells (Zwiebel et al., 1989), and myoblast cells (Dai et al., 1992; Lynch et al., 1992; Yao and Kurachi, 1992), have been intensively tested as target cells for gene therapy. Skin fibroblasts are one of the most attractive candidates because they offer several advantages, such as easy access, easy culture in vitro, efficient infection by retroviral vectors, as well as convenient reimplantation. In the present report, we are the first to demonstrate a persistent expression of pGH for at least 70 days from the im-

FIG. 3. Semiquantative analysis of pGH RNA level and the proviral genome DNA in the explanted grafts. RT-PCR analysis and genomic PCR analysis were used to semiquantify the RNA levels and the proviral DNA levels, respectively, in the explanted tissues (see Materials and Methods for the details of semiquantitative PCR). A. The quantitative nature of the semiquantitative PCR technique. Known amounts of RNA (left) or DNA (right) were taken from PSN-transduced REF cells. One microgram of total RNA or $0.05 \mu \mathrm{g}$ of genomic DNA was used to begin with the reaction. Serial dilutions (from 1- to 1,000 fold) were made by mixing the PSN-transduced primary REF cellular RNA (or DNA) with background REF cellular RNA (or DNA). The amplified PCR products were separated on a $2.5 \%$ agarose gel and hybridized with the pGH probe (upper bands) and the GAPDH probe (lower bands), respectively. The ratios of pGH/GAPDH band intensities were plotted against the percentages of pGH-specific RNA (or DNA) on logarithmic graph paper; an estimated best-fit line was drawn through plotted points. In both RT-PCR and genomic PCR analyses, rough linear correlations were obtained. The pGH RNA levels in the explanted tissue (B), and the percentages of vector DNA in the grafts $(C)$ were then calculated by using this plot based on the obtained values of $\mathrm{pGH} / \mathrm{GAPDH}$ band intensities. The specific expression efficiency of pGH RNA was then obtained by the ratio of (\% of pGH RNA level/\% of vector DNA), while with the corresponding ratio from the primary PSN-infected REF designated as 1 (C, lane 2). In B and C, lanes 1 are the samples prepared from plain REF; lanes 2, the PSN virus-infected REF; lanes 3, the collagen treated PSN-infected REF prior implantation; lanes 4-6, explants of day 5, lanes 7-9, explants of day 15 , lanes 10-12, explants of day 42 , and lanes $13-15$, explants of day 70 post-implantation. Lanes $16-18$ in B indicate the results of RT-PCR analysis on day- 42 explants where the reverse transcriptase was omitted from the first step of reverse transcription. a, b, and c denote the three mice used. 


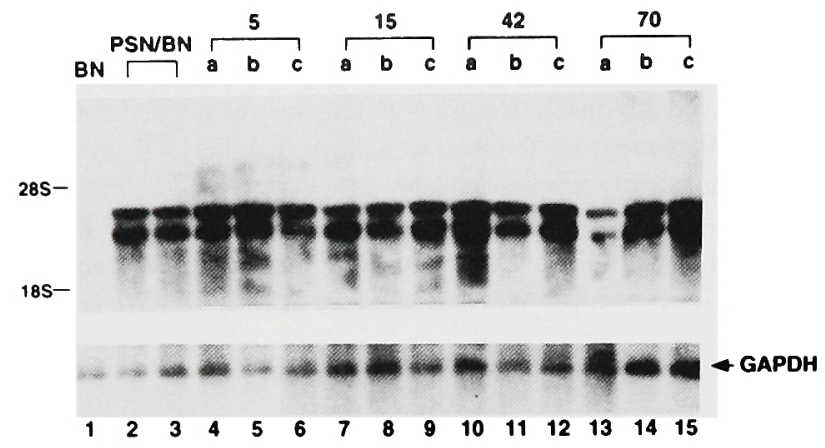

FIG. 4. Northern blot analysis of the G418-resistant cells initiated from the explanted grafts. Five micrograms of total RNA were analyzed by Northern blot analysis with pGH and GAPDH probes. Arrow indicate the GAPDH used as an internal control. The upper two bands are the predicted transcripts expressed from the proviral genome. The order of each lane is same as that described in the legend of Fig. 3B.

planted primary fibroblast cells in all 3 animals, albeit with reduced levels in the day-42 and the day-70 explants (Fig. 3B). The relative decrease, though not very precise because only a semiquantitative RT-PCR was performed, was reproducibly obtained when two independent experiments were carried out. These results, however, were not due to the lack of long-term RNA expression because when the genomic DNA from all three explants of day 42 and day 70 were checked, the pGH specific sequences was also reduced (Fig. 3C). This phenomenon indicated that the grafted tissue contained fewer vector-positive cells in the day-42 and the day-70 explants, and the results could be due to two possible reasons. First, an inefficient retrieval of the dermal grafts yielded low numbers of vector-positive cells in the explants. This occurred because when the dermal grafts were embedded, the skin was directly sutured, which caused the grafts to fuse totally with local connective tissue after a long period following implantation. We indeed had a difficult time of recovering the grafts at day 42 and day 70 post-implantation. Second, the implanted fibroblast cells gradually died after a long period post-implantation, resulting in big loss of transduced cells. This was quite conceivable because we did not simultaneously provide fibroblast growth factors with the grafts when cells were implanted, as previous reported (St. Louis and Verma, 1988). We speculated that the fibroblast cells cast in collagen matrices might not survive long enough. Both factors, however, should be able to be overcome in the future with the improvement of implantation techniques to maintain the cast cells survived as long as possible.

Despite the reduced levels observed, we were still able to demonstrate the persistent expression of pGH RNA for up to 70 days in all 3 animals tested. The results were evident either directly by RT-PCR analysis on the RNA from the explanted tissue, or indirectly by the G418 resistance conferred by the cells recovered from the explants. Furthermore, because the cell population used for RT-PCR analysis and genomic PCR analysis was from the same graft tissue, if the positivity of vector DNA retained in the explants was taken into consideration, the specific expression efficiencies of pGH RNA from all grafts taken at different time points turned out to be relatively con- stant (Fig. 3C). Our results were therefore opposed to the previous finding that the introduced gene was gradually inactivated in vivo within 1 month or so (St. Louis and Verma, 1988; Palmer et al., 1991). The discrepancies between our results and previous observations could be due to at least three possible reasons: (i) embryo fibroblasts instead of skin fibroblasts were used in our experiment; (ii) a bicistronic retroviral vector, containing one retroviral LTR promoter, offered a better possibility of long-term expression of a foreign gene in vivo than a vector with two promoters; and (iii) immune responses against the foreign protein occurred in previous studies, but not in ours.

In the St. Louis and Verma experiment, embryo fibroblast cells were employed but a gradual loss of human factor IX activity in mice after 15 days was observed (St. Louis and Verma, 1988). On the other hand, in the Hoeben et al. experiment, skin fibroblast cells were used, but they detected a persistent expression of human factor VIII in nude mice (Hoeben et al., 1993). Therefore, we think it is unlikely that the first reason, that we used embryo fibroblasts, explains the persistent expression of pGH in our results. The second reason also seems unlikely, but cannot be excluded. Both types of vectors, the bicistronic vector used in our study and the $\mathrm{X}$ series vectors used in previous studies, employ the retroviral LTR promoter to express pGH, human factor IX (St. Louis and Verma, 1988), and human adenosine deaminase (hADA) (Palmer et al., 1991), respectively. Therefore, it is hard to attribute the phenomena that the transduced gene was gradually inactivated in their studies but was persistently expressed in our study to the down-regulation of the LTR promoter in vivo. Differences in the backbone sequence and expression efficiency between these two types of vector are thus the possible reasons to explain the discrepancies, which, however, remains to be further investigated. Rather, we think that the third possibility is the most likely explanation for the persistence of pGH expression in our study. Because the $\mathrm{pGH}$ sequence is greatly homologous to that of rat GH (94\% homology, as analyzed by the Gap comparison program in GCG, Genetics Computer Group Sequences Analysis System), we assumed that immune responses would not be easily induced. Consistent with this notion, no xenoantibodies against pGH nor cytolytic T lymphocytes against the PSN-transduced REF cells were detected in our implanted animals (data not shown). Further supporting this third possibility, that the persistent expression of $\mathrm{pGH}$ in our study occurred because there was no immune response against pGH, Hoeben et al. demonstrated the capability of skin fibroblasts to express factor VIII of human species in immunodeficient mice persistently (up to 8 weeks) (Hoeben et al., 1993). Therefore, we believe that it is possible to use skin fibroblasts as vehicles for therapeutic gene expression if no immune responses against the foreign protein occur.

In St. Louis's results, because the sequence of human factor IX is more divergent from that of mouse factor IX (82.6\% homology, analyzed as described above), xenoantibodies against human factor IX were induced in the transplanted mice, thus explaining why the activity of human factor IX in the sera was lost after 15 days (St. Louis and Verma, 1988). However, the results from Palmer's experiments are inconsistent with our data (Palmer et al., 1991). They transduced hADA, an intracellular protein whose sequence is also different among different species (e.g., hADA and mouse ADA have only $83 \%$ homology), into 
rats by skin fibroblast cells and observed only a transient expression of hADA. But cellular- or antibody-mediated immunoresponses were not detected in their graft-transplanted animals. Thus, their results exclude the possibility that immune responses are involved in the inactivation of transduced genes in vivo. However, we speculate that it is still possible that a low level of immunoreactivity, particularly cellular immunity, was gradually induced against the foreign protein in their transplanted animals, but was undetected by their assay system and which eventually led to the inactivation of the transduced gene. Alternatively, differences in the genes, vectors, animal models, and ways of measuring the activities of the transduced proteins employed by different laboratories might explain why persistent expression was not observed in Palmer's experiments, but was observed in ours and in Hoeben's experiments.

During the detection of pGH expression, we failed in an attempt to detect the pGH protein directly in the sera of graft-implanted animals. This was because a sensitive ELISA system was not available to us. Because pGH is very homologous to the GH of mouse, rat, and rabbit, but less homologous to that of human $(69 \%$ ), we could not generate efficient monoclonal antibodies from mice or rats against pGH; on the other hand, the commercially available kit for human GH was not appropriate to our study. We could only obtain polyclonal antiserum from rabbit by a novel intrasplenical immunization protocol (Hong et al., 1989). Thus, a sensitive ELISA is a limitation in our hands. Therefore, in this study we did not have formal proof of the pGH protein in the sera. The tibia growth assay and RTPCR analysis were thus used instead to evaluate pGH expression. These assays, however, should be more effective than an ELISA.

The hypophysectomized animal system has been established as a standard bioassay system for growth hormone functions (Evans et al., 1943; Greenspan et al., 1949). We now applied it as an animal model for GH gene therapy. Because this system provides a direct in vivo functional assay for $\mathrm{GH}$, it circumvents the problems that occurred in many other animal models, in which only the protein level instead of the protein function was measured. Therefore, this system is very useful for gene therapy studies, especially focusing on various target cell types or long-term gene expression in vivo.

\section{ACKNOWLEDGMENTS}

We thank Jeny Lin and Dr. Pei-Jer Chen for careful reading and revision of this manuscript. This work was supported by grant NSC-82-0418-B002-098-BC from the National Science Council of the Republic of China.

\section{REFERENCES}

ARMENTANO, D., YU, S.F., KANTOFF, P.W., VON RUDEN, T., ANDERSON, W.F., and GILBOA, E. (1987). Effect of internal viral sequences on the utility of retroviral vectors. J. Virol. 61, $1647-1650$.

BELL, E., IVARSSON, B., and MERRILL, C. (1979). Production of a tissue-like structure by contraction of collagen lattices by human fibroblasts of different proliferative potential in vitro. Proc. Natl. Acad. Sci. USA 76, 1274-1278.
BURNETTE, W.H. (1981). Electrophorectic transfer of proteins from SDS-polyacrylamide gels to unmodified nitrocellulose and radiographic detection with antibody and radioiodinated protein A. Anal. Biochem. 112, 195-203.

CHEN, B.F., HSIEH, C.L., CHEN, D.S., and HWANG, L.H. (1992). Improved gene expression by a U3-based retroviral vector. Biochem. Biophys. Res. Commun. 184, 330-337.

CHEN, B.F., HWANG, L.H., and CHEN, D.S. (1993). Characterization of a bicistronic retroviral vector composed of the swine vesicular disease virus internal ribosome entry site. J. Virol. 67, 2142-2148.

CHOMCZYNSKI, P., and SACCHI, N. (1987). Single-step method of RNA isolation by acid quanidinium thiocyanate-phenol-chloroform extraction. Anal. Biochem. 162, 156-159.

DAI, Y., ROMAN, M., NAVIAUX, R.K., and VERMA, I.M. (1992). Gene therapy via primary myoblasts: Long-term expression of factor IX protein following transplantation in vivo. Proc. Natl. Acad. Sci. USA 89, 10892-10895.

DOTT, N.M. (1923). An investigation into the functions of the pituitary and thyroid glands. Part I. Technique of their experimental surgery and summary of results. J. Exp. Physiol. 13, 241-282.

DOTT, N.M., and FRASER, J. (1923). The influence of experimental pituitary and thyroid derangements upon the developmental growth of bone. Q. J. Exp. Physiol. 13, 107-108.

EVANS, H.M., SIMPSON, M.E., MARK, W., and KIBRICK, E. (1943). Bioassay of the pituitary growth hormone: Width of the proximal epiphyseal cartilage of the tibia in hypophysectomized rats. Endocrinology 32, 13-16.

FENJVES, E.S., GORDON, D.A., PERSHING, L.K., WILLIAMS, D.L., and TAICHMAN, L.B. (1989). Systemic distribution of apolipoprotein E secreted by grafts of epidermal keratinocytes: Implication for epidermal function and gene therapy. Proc. Natl. Acad. Sci. USA 86, 8803-8807.

FRESHNEY, R.I. (1983). Culture of Animal Cells: A Manual of Basic Technique. (Alan R. Liss, Inc., New York) pp. 107-110.

FREUD, J., LEVIE, L.H., and KROON, D.B. (1939). Observations on growth (chondrotrophic) hormone and localization of its points of attack. J. Endocrinol. 1, 56-64.

GARVER, R.I., J.R., CHYTIL, A., COURTNEY, M., and CRYSTAL, R.G. (1987). Clonal gene therapy: Transplanted mouse fibroblast clones express human $\alpha 1$-antitrypsin gene in vivo. Science $\mathbf{2 3 7}$, 762-764.

GERRARD, A.J., HUDSON, D.L., BROWNLEE, G.G., and WATT, F.M. (1993). Towards gene therapy for haemophilia B using primary human keratinocytes. Nat. Genet. 3, 180-183.

GREENSPAN, E.S., LI, C.H., SIMPSON, M.E., and EVANS, H.M. (1949). Bioassay of hypophyseal growth hormone: The tibia test. Endocrinology 45, 455-463.

HANDELSMAN, M.B., and GORDON, E.F. (1930). Growth and bone changes in rats injected with anterior pituitary extract. J. Pharmacol. Exp. Therapy 38, 349-362.

HANTZOPOULOS, P.A., SULLENGER, B.A., UNGERS, G., and GILBOA, E. (1989). Improved gene expression upon transfer of the adenosine deaminase minigene outside the transcriptional unit of a retroviral vector. Proc. Natl. Acad. Sci. USA 86, 3519-3523.

HOEBEN, R.C., FALLAUX, F.J., VAN TLLURG, N.H., CRAMER, S.J., VAN ORMONDT, H., BRIET, E., and VAN DER EB, A.J. (1993). Toward gene therapy for hemophilia A: Long-term persistence of factor VIII secreting fibroblasts after transplantation into immunodeficient mice. Hum. Gene Ther. 4, 79-186.

HONG, T.H., CHEN, S.T., TANG, T.K., WANG, S.C., and CHANG, T.H. (1989). The production of polyclonal and monoclonal antibodies in mice using novel immunization methods. J. Immunol. Methods 120, 151-157.

HWANG, L.H., CHEN, B.F., LEE, P.J., HO, S.Y., and LIU, J.J. (1992). Use of helper-free retroviral vector to direct a high expression of 
porcine growth hormone in mouse fibroblast cells. Biotechnol. Appl. Biochem. 16, 171-181.

KIBRICK, E.A., BECKS, H., MARX, W., and EVANS, H.M. (1941). The effect of different dose levels of growth hormone on the tibia of young hypophysectomized females rats. Growth 5, 437-447.

LAEMMLI, U.K. (1970). Cleavage of structural proteins during the assembly of the head of bacteriophage T4. Nature 227, 680-685.

LARON, Z., PERTZELAN, A., KARP, M., KOWADLOSILBERGELD, A., and DANGHADAY, W.H. (1971). Administration of growth hormone to patients with familial dwarfism with high plasma immunoreactive growth hormone: Measurement of sulfation factor, metabolic and linear growth responses. J. Clin. Endocrinol. Metab. 33, 332-342.

LYNCH, C.M., CLOWES, M.M., OSBORNE, W.R.A., CLOWES, A.W., and MILLER, A.D. (1992). Long-term expression of human adenosine deaminase in vascular smooth muscle cells of rats: A model for gene therapy. Proc. Natl. Acad. Sci. USA 89, 1138-1142.

MARKOWITZ, D., GOFF, S., and BANK, A. (1988). A safe packaging line for gene transfer: Separating viral genes on two different plasmids. J. Virol. 62, 1120-1124.

MARTIN, J.B. (1973). Neutral regulation of growth hormone secretion. N. Engl. J. Med. 288, 1384-1388.

MORGAN, J.R., BARRANDON, Y., GREEN, H., and MULLIGAN, R.C. (1987). Expression of an exogenous growth hormone gene by transplantable human epidermal cells. Science 237, 1476-1479.

PALMER, T.D., ROSMAN, G.J., OSBORNE, W.R.A., and MILLER, A.D. (1991). Genetically modified skin fibroblast persist long after transplantation but gradually inactivate introduced genes. Proc. Natl. Acad. Sci. USA 88, 1330-1334.

RAY, R.D., EVANS, H.M., and BECK, H. (1941). Effect of the pituitary growth hormone on the epiphyseal disk of the tibia of the rat. Am. J. Pathol. 17, 509-528.

ROSENBERG, M.B., FRIEDMANN, T., ROBERTSON, R.C., TSUZYNSKI, M., WOLFF, J.A., BREAKEFIELD, X.O., and GAGE, F.H. (1988). Grafting genetically modified cells to the damaged brain: Restorative effects of NGF expression. Science 242, $1575-1578$

SAMBROOK, J., FRITSCH, E.F., and MANIATIS, T. (1989). Molecular Cloning: A Laboratory Manual, 2nd ed., vol. 2. (Cold Spring Harbor Laboratory Press, Cold Spring Harbor, New York) pp. 9.14-9.19.
SELDEN, R.F., SKOSKIEWICZ, M.J., HOWIE, K.B., RUSSELL, P.S., and GOODMAN, H.M. (1987). Implantation of genetically engineered fibroblasts into mice: Implications for gene therapy. Science 236, 714-718.

SMITH, G.H., GALLAHAN, D., ZWIEBEL, J.A., FREEMAN, S.M., BASSIN, R.H., and CALLAHAN, R. (1991). Long-term in vivo expression of genes introduced by retrovirus-mediated transfer into mammary epithelial cells. J. Virol, 65, 6365-6370.

SMITH, P.E. (1930). Hypophysectomy and a replacement therapy in the rat. Am. J. Anat. 45, 205-273.

ST. LOUIS, D., and VERMA, I.M. (1988). An alternative approach to somatic cell gene therapy. Proc. Natl. Acad. Sci. USA 85, 31503154

TANI, K., OZAWA, K., OGURA, H., TAKAHASHI, T., OKANO, A., WATARI, K., MATSUDAIRA, T., TAJKA, K., KARASUYAMA, H., NAGATA, S., ASANO, S., and TAKAKU, F. (1989). Implantation of fibroblasts transfected with human granulocytes colony-stimulating factor cDNA into mice as a model of cytokinesupplement gene therapy. Blood 74, 1274-1280.

WILHELMI, A.E. (1974). Chemistry of growth hormone. In Handbook of Physiology, sect. 7, vol. 4, pt. 2. E. Knobil, and W.H. Sawyer, eds. (American Physiological Society, Washington DC) pp. 59-78.

YAO, S-N., and KURACHI, K. (1992). Expression of human factor IX in mice after injection of genetically modified myoblasts. Proc. Natl. Acad. Sci. USA 89, 3357-3361.

ZWIEBEL, J.A., FREEMAN, S.M., KANTOFF, P.W., CORNETTA, K., RYAN, U.S., and ANDERSON, W.F. (1989). High level recombinant gene expression in rabbit endothelial cells transduced by retroviral vectors. Science 243, 220-243.

\section{Address reprint requests to: Dr. Lih-Hwa Hwang Hepatitis Research Center National Taiwan University Hospital No. 1 Chang-Te Street Taipei 100, Taiwan, R.O.C.}

Submitted for publication October 20, 1994; accepted after revision March 22, 1995. 